\title{
Relações Sociais em Tempos de Isolamento Social e as Contribuições das TIC: Percepções e Reflexões na Região de Bauru-SP
}

\author{
Social Relations in Times of Social Isolation and the Contributions of ICT: \\ Perceptions and Reflections in the Bauru-SP Region
}

\section{Relaciones Sociales en Tiempos de Aislamiento Social y las Contribuciones de las TIC: Percepciones y Reflexiones en la Región de Bauru-SP}

\author{
David Gustavo Pompei \\ M.Sc.(c) Mídia e Tecnologia, FAAC/UNESP. Bauru, SP, Brasil. \\ Prefeitura Municipal de Pederneiras \\ gustavopompei07@gmail.com \\ (iD) https://orcid.org/0000-0003-4625-2628 \\ Camila Roberta Muniz Serra \\ Ph.D.(c) Mídia e Tecnologia, FAAC/UNESP. Bauru, SP, Brasil. \\ Instituição Toledo de Ensino de Bauru, Brasil \\ camilaserra@ite.edu.br \\ (iD) https://orcid.org/0000-0001-9856-4389 \\ Cassiana Anunciata Caglioni \\ Ph.D.(c) Comunicação, FAAC/UNESP. Bauru, SP, Brasil. \\ Instituição Toledo de Ensino de Bauru, Brasil \\ cassiana.caglioni@unesp.br \\ (i) https://orcid.org/0000-0003-4671-1572
}

Recibido: noviembre 9 de 2020

Aceptado: diciembre 11 de 2020

Publicado: diciembre 15 de 2020

\section{RESUMO}

Devido à Covid-19 e ao isolamento social, novas formas de relacionamento foram adotadas por meio das TIC. Nessa perspectiva, o objetivo deste trabalho busca discutir como as relações sociais foram impactadas por elas no período atual, bem como os desafios da interação social. A metodologia incluiu revisão bibliográfica, pesquisa de campo e análise de questionários aplicados por meio de um grupo do Facebook. Como resultados preliminares, refletiu-se que a crise local-global trouxe avanços e retrocessos. Portanto, as TIC contribuíram para as novas configurações das relações e interações sociais na cidade de Bauru. Ressalta-se que essas tecnologias ainda não superam as interações desenvolvidas na esfera pessoal.

Palavras-chave: Relações Sociais; Tecnologias da informação e comunicação; Isolamento social; Pandemia 


\section{ABSTRACT}

Due to Covid-19 and social isolation, new ways of relating were adopted through ICT. In this perspective, the objective of this work seeks to discuss how social relationships were impacted by them during the present period, as well as the challenges of social interaction. The methodology included a bibliographic review, field research and analysis of questionnaires applied through a Facebook group. As preliminary results, it was reflected that the local-global crisis brought progress and setbacks. Therefore, ICT contributed to the new configurations of social relationships and interactions in the city of Bauru. It is emphasized that these technologies still do not overcome the interactions developed in the personal sphere.

Keywords: Social Relations; Information and Communication Technologies; Social Isolation; Pandemic.

\section{RESUMEN}

Debido a la Covid-19 y al aislamiento social, nuevas formas de relacionarse fueron adoptadas por medio de las TIC. En esta perspectiva, el objetivo de este trabajo busca discutir cómo las relaciones sociales fueron impactadas por estas durante el presente periodo, así como los desafíos de la interacción social. La metodología contó con revisión bibliográfica, investigación de campo y análisis de cuestionarios aplicados a través de un grupo de Facebook. Como resultados preliminares, se reflexionó que la crisis local-global trajo consigo avances y retrocesos. Por tanto, las TIC contribuyeron en las nuevas configuraciones de las relaciones e interacciones sociales en la ciudad de Bauru. Se destaca que estas tecnologías aún no superan las interacciones desarrolladas en el ámbito personal.

Palabras clave: Relaciones Sociales; Tecnologías de la Información y la Comunicación; Aislamiento Social; Pandemia.

\section{INTRODUÇÃO}

Com o avanço tecnológico das últimas décadas e, mais especificamente, o avanço da comunicação no século XXI, fica quase impossível não se identificar o amplo acesso à informação e as formas de relacionamento entre as pessoas através da conectividade com a internet por meios das Tecnologias da Informação e Comunicação (TIC). Esses avanços trouxeram recursos tecnológicos que reduziram custos de deslocamentos, ampliaram as formas de educação formal, a exemplo, a educação à distância, cursos online, vídeos conferências, além de outras formas de redução de custos, sem deixar de considerar a economia através das vendas online. Neste sentido, podemos pontuar (McLuhan, 2007, p.63), afirmando que "qualquer invenção ou tecnologia é uma extensão ou auto amputação de nosso corpo, e essa extensão exige novas relações e equilíbrios entre os demais órgãos e extensões do corpo".

O que se observa é que com a inserção das mídias e das redes sociais na vida das pessoas, parece ter se padronizado um novo tipo de interação entre as relações humanas e de consumo, ou seja, as formas como as pessoas interagem no dia a dia demandou uma adaptação seja no modo de relacionamento pessoal, seja no modo profissional a partir do uso das TIC, fato que pode ser ampliado a partir de março de 2020, período em que Organização Mundial de Saúde declara como pandemia o novo Coronavírus e que o isolamento social é uma das alternativas de prevenção.

Neste sentido, é importante considerar uma sociedade predominantemente urbanizada, que vem desenvolvendo e atualizando as tecnologias e que tem estabelecido novas formas de negócios (Bezerra e Cunha, 2020). Por esta perspectiva, o uso de TIC para compras, contatos familiares, trabalho, entre outras ações cotidianas, teve sua ampliação e novas formas de relacionamento se efetivaram a partir deste contexto.

Neste cenário, o objetivo deste trabalho visa discutir como as relações sociais estão sendo impactadas por conta do isolamento social e como as TIC trouxeram contribuições ou aumentaram os desafios neste momento para a cidade contemporânea. Para tanto foi desenvolvida uma revisão bibliográfica que subsidiou a pesquisa aplicada através de um questionário online aplicado junto ao grupo "SOS Coronavírus Bauru" mantido pela rede social Facebook, sendo, em seguida, apresentados os resultados a análises conclusivas preliminares.

O isolamento social e a necessidade de interação social durante o período de pandemia de Covid-19 
No início de 2020, a pandemia do novo Coronavírus, proporciona ao Brasil e ao mundo o enfrentamento de uma emergência com gravíssimas consequências para "a vida humana, a saúde pública e a atividade econômica" (Caetano, et al., 2020, p.2). O surgimento de vários casos graves de um novo tipo de Coronavírus, antes não presente em seres humanos, foi identificado (2019$\mathrm{nCoV}$ ), o que despertou um alerta à Organização Mundial da Saúde (OMS) em 31 de dezembro de 2019, conduzindo a declarar, em 30 de janeiro de 2020, um surto do novo vírus. Em 11 de março, a Covid-19 foi caracterizada como uma pandemia, termo que se refere à distribuição geográfica de uma doença (Caetano, et al., 2020).

A contaminação foi identificada em mais de 180 países e diante da proliferação da doença, autoridades governamentais vêm adotando estratégias para reduzir o ritmo da progressão da doença (Pereira et al., 2020). Neste contexto, pesquisadores e profissionais da área da saúde encontram-se diante do desafio deste avanço no número de casos de Covid-19, uma vez que esta não possui o risco clínico totalmente definido, como também não se conhece com exatidão o padrão de transmissibilidade, infectividade, letalidade e mortalidade.

A doença apresenta elevada transmissibilidade; grande contingente de indivíduos infectados e adoecidos ao mesmo tempo representa risco de sobrecarga para o atendimento dos sintomáticos e dos graves, podendo gerar estrangulamento do sistema de saúde e elevar significativamente a letalidade da doença. A instituição de medidas amplas de distanciamento social, com fechamento de estabelecimentos e cancelamento de eventos com grande público, de isolamento e de quarentena é fundamental para que ocorra uma desaceleração da propagação da epidemia (Caetano, et al., 2020, p.2).

Neste sentido, adota-se primeiramente o distanciamento social, evitando aglomerações, recomendando manter no mínimo um metro e meio de distância entre as pessoas e a proibição de eventos que gerem um grande número de pessoas reunidas (Pereira et al., 2020). Os autores explicam que em casos extremos é adotado o Isolamento Social (IS), definido como a proibição das pessoas em sair de suas casas como forma de evitar a proliferação do vírus.

Diante deste contexto, torna-se primordial a atenção voltada à saúde mental coletiva e individual, pois é próprio do ser humano pensar, se emocionar e interagir. Nessa perspectiva, juntamente com a pandemia de Covid-19 emerge na sociedade em nível global, um estado de pânico desencadeado pelas estratégias de distanciamento e isolamento social, gerando sentimentos como angústia, insegurança e medo, que inclusive podem permanecer além da pandemia (Pereira, et al., 2020).

Isto se dá porque somos seres multidimensionais, com aspectos físicos, psicológicos, espirituais e sociais. Lima e Pitta (2019) definem como necessidades humanas ou básicas, relacionadas às necessidades existenciais, sociais e culturais. Para as autoras as necessidades básicas são as de consumo, ou seja, as necessidades do capital. Neste sentido, Altamirano e Ponce (2020) complementam que uma crise local-global desencadeia um desequilíbrio no ecossistema, proporcionando várias repercussões em retrocessos, mas sem dúvidas proporciona também avanços significativos.

Gomes Júnior e Pereira (2013, p. 6) corroboram ao trazer o contexto das TIC afirmando que "[...] a vida online substitui a participação popular nas lutas, pela adesão subliminar, silenciosa". E neste contexto, a cidadania acaba se confundindo com o poder de consumo, interferindo significativamente nas relações sociais (Lima; Pitta, 2019) e impactando nas dinẩmicas do sistema urbano.

\section{Impactos da pandemia no cenário urbano}

O impacto do isolamento social pode se tornar diferente entre as culturas. De acordo com Sayuri (2020, p.1) "acredita-se que sociedades mais 'abertas', como o Brasil, lidem com a condição de isolamento sob mais estresse e tensões, do que sociedades mais 'fechadas', como o Japão".

A autora define tais comportamentos como mobilidade relacional, considerada uma área interdisciplinar capaz de analisar as tendências de comportamento das sociedades em relação aos relacionamentos. Pode ser considerada uma "variável socioecológica". Desta forma, uma sociedade de alta mobilidade relacional seria mais aberta, passional e sociável, ou seja, uma sociedade de baixa mobilidade relacional, seria mais fria, fechada e reservada. No contexto da pandemia de Covid-19, a mobilidade deve diminuir no mundo todo.

Se as sociedades estão se fechando mais na atual pandemia, portanto, há consequências negativas e positivas possíveis: de um lado, mais desconfiança, como as demonstrações de preconceito contra a China, primeiro epicentro de Sars-Cov-2; de outro, mais de flexibilidade de atitudes individuais em prol do grupo, como a campanha digital \#FicaEmCasa, 
incentivando a autoquarentena para frear infecções no Brasil (Sayuri, 2020, p.1).

Torna-se necessário avaliar as particularidades de cada região, cada sistema urbano, pois as condições climáticas, culturais e econômicas contribuem de forma diferente para a proliferação do vírus ressaltando dificuldades, se pensarmos nas condições precárias de infraestrutura das regiões mais vulneráveis das cidades como: "favelas, bairros periféricos, comunidades ribeirinhas, assentamentos informais e de refugiados em todo o mundo" (Bezerra e Cunha Junior, 2020, p.2). Os autores afirmam ser cada vez mais comum evidenciar a "crise das cidades" e seus espaços públicos, que precisam ser vivos, seguros, sustentáveis e saudáveis.

No Brasil, de acordo com a pesquisa realizada "Impactos da Covid-19 nos Municípios", uma das áreas mais impactadas pela pandemia do novo coronavírus no âmbito dos municípios brasileiros foi a educação, seguida pela geração de empregos. Em relação à violência contra a mulher, para aproximadamente metade dos gestores entrevistados, este índice se manteve estável durante a pandemia. Porém, as respostas de cerca de dois quintos afirmaram que houve aumento de casos (Campos, 2020). Neste contexto, podemos citar o conceito de resiliência urbana que tratase da capacidade dinâmica do sistema urbano, de lidar com os problemas e, ao mesmo tempo, adaptar-se a mudanças, superar obstáculos e simultaneamente resistir à situações adversas (Meerow; Newel; Stults, 2016).

Ao mesmo tempo que as cidades são sistemas complexos, são também vulneráveis. Assim, uma cidade resiliente não retorna ao seu estado anterior após o processo de ruptura sofrido, mas se torna diversa (Dapiné, 2020) E neste sentido, as TIC poderiam se tornar soluções que contribuem no dinamismo e resiliência com foco nos desafios presentes nas cidades durante a pandemia.

\section{Tecnologias da Informação e Comunicação (TIC) e relações sociais}

Com a informatização ficou mais fácil e acessível de se encontrar grupos, ideias similares que corroboram para que um determinado comportamento exista; mesmo que num passado recente não fosse aceitável e neste aspecto, é dado o momento de repensar nossos valores, de modo que possamos manter nossa sociedade e o meio ambiente saudáveis e sustentáveis.
Nesteaspectoestamossendorealmente desafiados, pois valores como respeito, solidariedade e amor passaram a ser tratados com a mesma liquidez que a modernidade nos traz as informações e produtos de desejos. Segundo Bauman (2009, p.7), "a liquidez da vida e da sociedade se alimentam e se revigoram mutuamente", ou seja, a vida e a "sociedade líquido-moderna, não podem manter a forma ou permanecer por muito tempo", e o tempo tornou-se uma preciosidade, não temos tempo a perder com sentimentalismos.

Altamirano e Ponce (2020) ressaltam que a existência de uma ameaça à saúde impactou todas as atividades e comportamentos sociais, obrigando a humanidade a reconfigurar suas dinâmicas e percepções diante das mudanças emergentes, inclusive nas relações sociais.

Como afirmam Jenkins, Ford e Green (2014, p.65), "o advento da computação ligada em rede e a maneira como seus componentes vêm sendo absorvidos pela cultura participativa e distribuídos pelos sites de redes sociais, representam uma nova configuração de práticas que já existem há muito tempo", porém, fazem parte das inovações no amplo cenário das interações, inclusive por redes e mídias sociais.

Para que possamos ilustrar o conceito de rede e mídias sociais, Altermann (2010) nos explica que "uma rede social é um grupo de pessoas que têm algum nível de relação ou interesse mútuo". No entanto, para ele essa definição acabou ganhando um novo significado na internet, o que já foi chamado de "relationship site" (sites de relacionamento), hoje conhecidos como redes sociais, que é justamente a proposta de serviços como o Facebook e Twitter, ou seja, são redes sociais que se baseiam em relações online com as pessoas que você tem alguma ligação e/ou interesse em comum.

Ainda segundo Altermann (2010), em relação às mídias sociais, essas ganharam um novo significado graças à internet, pois o que há pouco tempo, se referia ao poder de "difundir uma mensagem de forma descentralizada" dos grandes meios de comunicação de massa, atualmente são traduzidos por muitos por "ferramentas online que são usadas para divulgar conteúdos, ao mesmo tempo que permitem uma relação com outras pessoas". Como por exemplo, um Blog que dissemina conteúdos e abre espaço para os leitores interagirem. Contudo, são ferramentas que objetivam o compartilhamento de conteúdo, sendo as relações em segundo plano. 


\section{As ferramentas de comunicação online e as relações sociais}

Segundo Bauman e Donskis (2014, p.11) estamos vivenciando um mundo em que os contrastes da riqueza e do poder estão em constante crescimento e trazendo consigo, não somente inseguranças ambientais, mas também conflitos pessoais que, via redes sociais, pessoas tornam-se mundialmente conhecidas, mesmo que não haja entre elas algo em comum. Um exemplo disso são os políticos que, graças à democracia e a educação em massa, criam condições ilimitadas de manipulação da sociedade, mesmo embora dependam das mudanças de atitudes da sociedade, bem como por ela possam ser destruídos.

Para os autores, "tudo é permeado pela ambivalência. Não há mais uma situação social inequívoca" e se você não está em uma rede social, não está em lugar algum. De fato, estamos vivendo numa realidade de possibilidades, não de dilemas como no passado recente. Neste campo, aproveitase o ensejo para atribuir ao "podemos" a pecha de organização manipuladora (Castells, 2017, p.237).

Assim, no campo da comunicação, uma nova narrativa é criada no espaço virtual, ou seja, nos smartphones, na tela dos computadores e das TV's digitais. E a partir daí, criou-se um novo desafio que é a busca da sensibilidade, das novas maneiras de agir em estrita colaboração entre as ciências humanas e sociais, para uma mútua compreensão em termos globais, no bojo da crítica social e auto interpretação. Martino (2014) enfatiza que em um mundo confuso, fragmentado e desconectado, a internet oferece outras formas de conexão e sociabilidade que cabem neste contexto. $\mathrm{O}$ autor cita que os links que acessamos online são o reflexo da nossa vida offline.

Para Bauman e Donskis (2014, p.13), o desafio atual está na unificação do pensamento e das ações, abertura pragmática e ética, assim como razão e imaginação. Para isto, exige-se não apenas a estratégia sempre autorrenovada de representar e elaborar o mundo, mas também de apreender e debater os problemas, promovendo o diálogo por meio de uma escrita que não crie barreiras, pois se a filosofia, a literatura e o jornalismo não caminharem juntos, todos poderão se tornar "bárbaros", além do distanciamento, competitividade e individualismo, que já se observam. Inclusive levando para os relacionamentos interpessoais, ou seja, não há espaço para a moral.

Com isto, o que podemos observar é que o mal, não está apenas confinado às guerras ou às ideologias como no passado, mas se revela quando nos deixamos de nos sensibilizar pelas outras pessoas, quando nos recusamos a compreendê-las, quando evitamos o olhar ético. A maldade está invisível e cada vez mais banalizada e qualquer pessoa está sujeita à sua ação, assim como Mcluhan $(2007$, p.72) afirma que "os meios, como extensões de nossos sentidos, estabelecem novos índices relacionais", não apenas em sentidos particulares, mas também entre si, na medida em que se inter-relacionam.

Observamos, também, que a alienação social simula a amizade nas redes sociais e nela, nos esquecemos de reconhecer "o outro", estamos nos recusando em admitir as diferenças, os outros tipos de pessoas, ao mesmo tempo que estamos descartando alguém vivo, real, e que está fazendo e dizendo alguma coisa ao nosso lado. Estamos talvez vivendo numa outra realidade semiótica. E assim, novas formas de censura coexistem, de maneira estranha, com a linguagem sádica e que corre solta nas orgias verbais do ódio sem face, onde se demonstra incomparáveis insensibilidades humanas, em especial nos comentários anônimos. É necessário devolver a dignidade, da mesma forma que a ideia da inescrutabilidade essencial dos seres humanos (Bauman, Donskis, 2014, p.18).

Ao abordar qualitativamente as relações, Martino (2014) destaca que a qualidade dos relacionamentos reais que migravam para o mundo digital era consideravelmente menor do que a relação com as pessoas conhecidas diretamente no ambiente virtual. Para os autores, a troca de informações e a construção de uma história acontecem nos ambientes virtuais e offline, porém, existe uma dificuldade em manter online uma amizade que começou offline.

Turkel apud Martino (2014), contextualiza as relações sociais a partir do uso de mídias digitais, enfatizando que quanto mais as pessoas se conectam, mais solitárias elas ficam. Segundo a autora, a conexão está relacionada com o medo que teríamos de nos vincular com as pessoas e estas nos deixariam sós um dia. A conexão também elimina algumas dificuldades que poderiam existir pessoalmente, como manter uma imagem, por exemplo, como fazemos quando escolhemos uma foto para as redes sociais. Tecnologias suprem as necessidades de comunicação e convivência, também geram outras formas de vida social, uma solidão coletiva. Neste sentido, Castells (2017), afirma que

$\mathrm{Na}$ era da internet, os indivíduos não se isolam na realidade virtual, pelo contrário, eles expandem sua sociabilidade usando a riqueza das redes de comunicação a sua disposição, mas o fazem de maneira seletiva, construindo seu mundo cultural 
em termos de preferências e projetos, modificandoos de acordo com a evolução de seus interesses e valores pessoais (Castells, 2017, p.174).

A urgência do tempo em que estamos vivendo, é reconhecer que ao contrário do significado estrito de comunidade (lugar onde vivemos), as redes são construídas individualmente, e como tal remodeladas ou desfeitas, baseada apenas na vontade individual de persistir em permanecer num alicerce volátil. Neste sentido, é preciso nos perceber em uma realidade onde o modelo-padrão que estamos adotando é o da relação-mercadoria e transplantando esses padrões para as relações inter-humanas. Para Bauman e Donskis (2014, p.23), "uma atitude consumista pode lubrificar as rodas da economia, e ela joga areia nos rolamentos da moral" e isto, afeta não somente a vida, mas a saúde das pessoas e da sociedade.

Altamirano e Ponce (2020) ressaltam ser necessário assimilar um novo momento, um estado mental para, desta forma, trabalhar na potencialização do "comportamento intelectual, social e produtivo como um novo estilo de vida" (Altamirano; Ponce, 2020, p.5). Assim, pensar na realidade da sociedade moderna, a utilização das mídias e redes sociais, bem como as relações humanas, coloca-nos frente a um desafio de nos repensar, principalmente no que se refere às formas de relacionamentos, a superficialidade do conhecimento, o fortalecimento de vínculos, bem como os padrões atuais de comportamento que a utilização dos recursos de comunicação está gerando, de modo a trazer à luz do conhecimento, mecanismos de utilização saudáveis da tecnologia, nos reconhecendo como seres humanos e humanizados.

Diante desta realidade, não obstante do reconhecimento da maior oferta de informações, temos que lidar com as questões emergentes que nos submete a uma reflexão na possibilidade de reestabelecer a ordem das coisas e criarmos condições menos prejudiciais de produzir e inserir a tecnologia na vida e nos relacionamentos, pois a tecnologia permite nos aproximarmos do que está distante, contudo, também a nos distanciar do que está perto. Hoje estamos sem tempo de "respirar", de refletir, para o ócio que pode ser fonte de criatividade e principalmente, para nos relacionar, ouvindo o que nos é dito e saber lidar com isso; precisamos reaprender a olhar nos olhos das outras pessoas e ter condições de interpretar o outro para que possamos urgentemente resgatar nossa essência humana.

Neste sentido, McLuan (2007, p.88), afirma que nossos sentidos estão sendo deturpados, e a partir disto, "poucos direitos nos restam quando submetemos nossos sistemas nervoso e sensorial à manipulação particular daqueles que procuram lucrar arrendando nossos olhos, ouvidos e nervos" e isso seria o mesmo que transferir a conversação comum para uma empresa particular ou dar a atmosfera terrestre em monopólio a uma companhia. Assim, se enfocarmos a lógica social e as práticas culturais que favoreceram e popularizaram as plataformas midiáticas, sugerese que "as facilidades da mídia digital funcionam como catalisadoras para a reconceituação de outros aspectos da cultura" e até mesmo reconfigurar as estruturas legais, no que diz respeito à participação cultural, política e expectativas econômicas (Jenkins; Ford; Green, 2014, p.25).

Por outro lado, segundo Castells (2017, p.458), esse novo sistema de comunicação transforma radicalmente o espaço, o tempo e as dimensões fundamentais da vida humana. Ou seja, locais ficam despojados de seu sentido cultural, histórico e geográfico e reintegram-se em redes funcionais ou em colagens de imagens, ocasionando um espaço de fluxos que substitui o espaço de lugares. Para o autor, "o tempo é apagado nesse novo sistema de comunicação, já que passado, presente e futuro podem ser programados para interagir entre si na mesma mensagem". E assim, o espaço de fluxos e o tempo intemporal são as bases principais de uma nova cultura, que transcende e inclui a diversidade dos sistemas de representação historicamente transmitidos, ou seja, a cultura da realidade real, em que o faz de conta vai se tornando realidade.

Impõem-se considerar que, diante de tal cenário, os arquitetos e planejadores urbanos devem estar atentos às novas demandas que se apresentam nesse momento. Já é nítida a fragmentação do espaço-tempo imposta pela pandemia, impactando nas relações de trabalho, deslocamento, e no convívio social da população, cada vez mais dependente da dimensão tecnológica, o que acaba repercutindo no surgimento de novos hábitos e modos de vida. Esses novos hábitos também se devem a popularização dos smartphones, que influenciou significativamente a forma como nos relacionamos e nos comunicamos. Bezerra e Cunha Junior (2020) afirmam que sem tais artefatos tecnológicos, este cenário global de crise social e isolamento seria ainda mais difícil. Por outro lado, existem discussões que consideram a crise social anterior ao cenário de pandemia, ou seja, a do espaço físico e real que ocupamos.

\section{Delineamento da Pesquisa}

A presente pesquisa objetiva discutir como as relações sociais estão sendo impactadas 
por conta do isolamento social e como as TIC trouxeram contribuições ou aumentaram os desafios neste momento contemporâneo. Tem-se como hipótese a de que a de que em plena época de pandemia e isolamento social, as relações sociais experimentaram novas configurações que necessitaram ultrapassar o limite do contato físico, abrindo espaços para que o relacionamento social pudesse ser ressignificado, assim como novas formas de interação social através das TIC.

A metodologia foi elaborada com base na revisão bibliográfica que subsidiou a pesquisa quantiqualitativa aplicada, ambas com fins exploratórios.

A pesquisa aplicada foi realizada entre os meses de julho e agosto de 2020, sendo constituída por um questionário online realizado junto ao grupo de Facebook "SOS Coronavírus Bauru", que tem cerca de 2.500 participantes. A amostra empregada foi por conveniência, tendo a participação de 107 pessoas.

O questionário aplicado foi composto por 20 perguntas fechadas e abertas, construídas para delimitar o perfil dos respondentes e analisar quais contribuições ou desafios que as Tecnologias da Informação e Comunicação (TIC) têm trazido às relações sociais. Após a aplicação e tabulação dos dados, aplicou-se a análise descritiva e interpretação à luz das teorias discutidas na revisão bibliográfica alinhando à hipótese proposta.

\section{Apresentação e Análise dos dados}

Optou-se na apresentação por dois blocos de análise, sendo que o primeiro bloco tem como objetivo traçar o perfil das pessoas pesquisadas, contando com perguntas acerca da sua idade, gênero, formação, atuação profissional e acesso às TIC e o segundo bloco busca analisar a opinião dos pesquisados sobre as contribuições ou desafios que as Tecnologias da Informação e Comunicação (TIC) têm trazido às relações sociais em tempos de isolamento social, buscando evidenciar os dados que apresentaram maior relevância e repetição.

Bloco 1 - Perfil: idade, gênero, formação, atuação profissional e acesso às TIC, apresentados os dados por meio das figuras e das análises abaixo:

Observa-se que as pessoas participantes da pesquisa identificam-se do sexo feminino e como cis gênero (cuja identidade de gênero corresponde ao gênero que lhe foi atribuído no nascimento), sendo que o maior número de pessoas responderam ser casadas e a predominância de idade está entre 30 a 49 anos, representando $55,10 \%$. A maioria destas pessoas (85\%) é residente em Bauru e 56,10\% tem ensino superior completo, sendo que deste percentual, 29,90 concluiu pós-graduação.

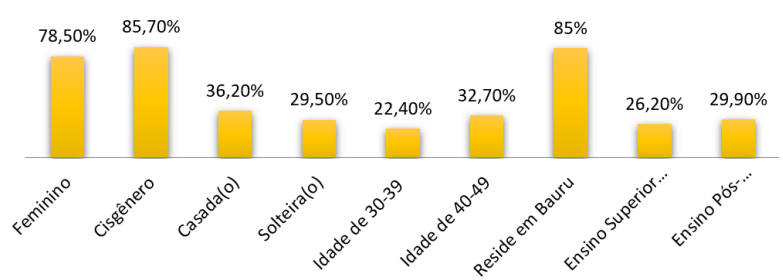

Figura 1. Perfil das pessoas pesquisadas. Fonte: Pesquisador(as) (2020).

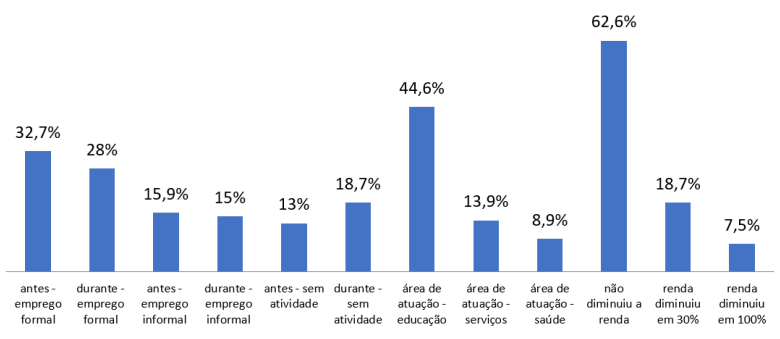

Figura 2 - Área de atuação, situação empregatícia e de renda das pessoas pesquisadas antes da pandemia e no momento presente. Fonte: Pesquisador(as) (2020).

Quando pesquisou-se sobre a empregabilidade antes e durante o período da pandemia, foi possível observar que apenas 32,7\% apresentavam-se com emprego formal, sendo que destes $4,7 \%$ acabaram perdendo a formalidade empregatícia durante o período da pandemia, sendo que essa mesma linha de diminuição de vínculos aplicou-se aos trabalhos informais. Infere-se que esta baixa nos números esteja relacionada às áreas de atuação das pessoas pesquisadas que podem ter sido impactas neste período como a área educacional $(44,6 \%)$ e serviços $(13,9 \%)$.

Entretanto quem estava sem atividade (13\%), conquistou uma atividade durante a pandemia representando $5,7 \%$ a maioria das pessoas pesquisadas que conquistaram uma atividade, o que pode estar relacionada à área de atuação da saúde, pois $8,9 \%$ atuam nesta área, que foi bastante requisitada no momento da pandemia. Quanto à renda, vale destacar $62,6 \%$ não tiveram diminuição de seus recebimentos e outros $18,7 \%$ e $7,5 \%$ tiveram a diminuição da renda em 30 e 10\% respectivamente. Também acrescenta-se que $88,6 \%$ não recebeu auxílio emergencial do governo e 9,5\% recebeu o apoio desta política pública. 


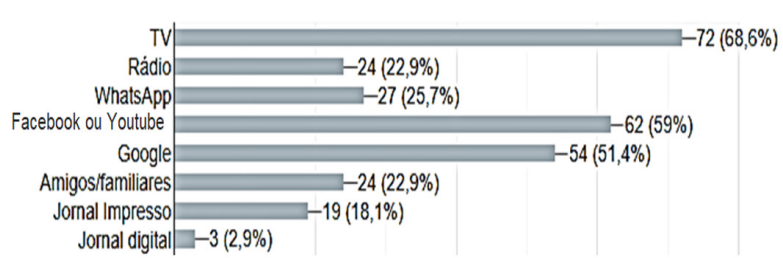

Figura 3. Uso das TIC para se informar no período de pandemia.

Fonte: Pesquisador(as) (2020).

Pela pesquisa permitir mais de uma escolha, observa-se nesta questão que a televisão, Facebook e Google foram os canais mais destacados pelas pessoas pesquisadas quando buscava-se informações referentes ao momento da pandemia, valendo ressaltar que apenas $1 \%$ dos pesquisados consideraram como fontes oficiais sites do governo por exemplo, trazendo uma possibilidade de inferência à credibilidade passada pelas políticas públicas neste período de pandemia, que, no Brasil passou por momentos de polarização e de questionamentos da pesquisa e ciência.

Já o Bloco 2 apresenta a opinião dos pesquisados sobre as contribuições ou desafios que as TIC têm trazido às relações sociais em tempos de isolamento social, sendo apresentadas as observações e análises abaixo.

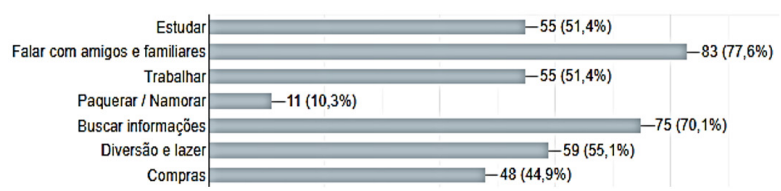

Figura 4. Em que as TIC e redes sociais mais contribuíram no período de pandemia. Fonte: Pesquisador(as) (2020).

Nesta pergunta que permitia escolher mais de uma alternativa, observa-se que as pessoas pesquisadas utilizaram as Tecnologias de informação e de comunicação para falar com amigos, pesquisar informações, ter momentos de lazer, estudos, trabalho e realizar compras, conforme justificativas abaixo:

Acredito que os contatos entre as pessoas se fortaleceram muito mais. Mudou a forma de se relacionar atualmente. Está ajudando a superar o grande trauma que a pandemia trouxe. Participante 6.

Como forma de divulgar meu trabalho, expor alguns ideais, e para me comunicar com as pessoas com quem não tenho mais contato pessoal. Participante 28.
Graças às redes sociais digitais minhas aulas na faculdade não precisaram ser interrompidas, ou seja, meu período de formação permanece o mesmo. Participante 34.

Aproximar as pessoas e contribuir com o sentimento de unidade entre todos, ajudou a nos manter próximos mesmo com o isolamento e também perceber que estamos "no mesmo barco", alguns de $1^{\text {a }}$ classe e outros de empregados do barco, mas se afundar morrem todos. Participante 50

Já quando foi perguntado em que as TIC e redes sociais impactaram negativamente no período de pandemia, $87 \%$ destacaram a disseminação de informações falsas, $37 \%$ reforçaram a grande quantidade de informação, $21 \%$ reforçou o distanciamento das afetividades, 9,3\% entendeu que o home office não foi uma boa experiência e $7,5 \%$ destacou que não houve impacto negativo. Esta questão também permitiu mais de uma resposta, destacando-se:

Trabalho na Educação os pontos negativos são que meus alunos da Educação Infantil não terem acesso (por motivos diversos, inclusive financeiro) ao material que estamos produzindo e que estamos trabalhando MUITO além de nossa carga horária diária, pois acabamos ficando à disposição praticamente o dia todo. Participante 19.

Aumento significativo de publicações falsas, apologia a crimes de ódio e terrorismo constantes, e falta de conhecimento real e embasamento para se criar argumentos válidos, negacionismo, agressões verbais por fanatismo político. Participante 45.

Grande número de informações antigas ou falsas. Causando atitudes negativas, violentas, e falta de credibilidade em relação a gestão do país por parte dos governantes. Participante 103.

Muitas informações falsas com receitas milagrosas,acabaram confundindo e desinformando. Participante 107.

Quando questionados sobre as relações sociais antes e durante a pandemia, observou-se que a maioria dos(as) respondentes destacaram que as relações sociais eram mais próximas e afetuosas antes. Já as pessoas pesquisadas reforçam que durante a pandemia, embora as TIC não substituam o contato pessoal, puderam proporcionar uma maneira de trazer uma aproximação com familiares, amigos, trabalho e estudos, como mostra-se nos comparativos abaixo apresentados: 
Pompei et al. - Relações Sociais em Tempos de Isolamento Social e as Contribuições das TIC

\begin{tabular}{|c|c|c|}
\hline Respondente & $\begin{array}{l}\text { Como as suas relaçöes eram ANTES da } \\
\text { pandemia? }\end{array}$ & $\begin{array}{l}\text { Como as suas relações estão NO MOMENTO } \\
\text { ATUAL da pandemia? }\end{array}$ \\
\hline 8 & $\begin{array}{l}\text { Já tinha o uso da internet pra se relacionar, mas } \\
\text { com a pandemia aumentou na vida das pessoas }\end{array}$ & Estamos distantes e nos trouxe mais sensibilidade \\
\hline 11 & Sempre em companhia de familiares e amigos & $\begin{array}{l}\text { Afastados fisicamente, mas sempre conectados } \\
\text { pelas redes sociais. É o que nos resta }\end{array}$ \\
\hline 14 & $\begin{array}{l}\text { Havia mais interação entre os amigos e familiares } \\
\text { (contato fisico) encontros e passeios aconteciam } \\
\text { diariamente. Uma boa comunicação com todos!!! }\end{array}$ & $\begin{array}{l}\text { Contato físico somente com a família interna, um } \\
\text { relacionamento agradável e cheio de descobertas }\end{array}$ \\
\hline 21 & Muito contato físico - estar com o outro. & Em isolamento, somente pelas redes sociais \\
\hline 49 & Próximas com as pessoas da família e do trabalho. & $\begin{array}{l}\text { Contato virtual com os familiares e colegas de } \\
\text { trabalho e pouco contato presencial }\end{array}$ \\
\hline 55 & Mais seguras e próximas & Virtuais, mas próximas \\
\hline 92 & Saía mais & $\begin{array}{l}\text { Mais distanciada fisicamente } \\
\text { Mas dá para comunicar muito pela internet }\end{array}$ \\
\hline 101 & Leves e despreocupadas & $\begin{array}{l}\text { Tensas, porém buscando ao máximo explorar a } \\
\text { aproximação que as redes sociais proporcionam }\end{array}$ \\
\hline 104 & Contato afetivo significativo & Seguem sem contato físico \\
\hline
\end{tabular}

Tabela 1. Relações sociais antes e durante a pandemia Fonte: Pesquisador(as) (2020).

Por esta perspectiva acrescenta-se que as pessoas pesquisadas destacaram a maneira de como o meio digital influenciou as suas relações humanas no período de pandemia, conforme apresentado abaixo:

Em manter o contato, mesmo distante de corpos pudemos compartilhar alguns momentos através do meio digital. Até casamento e aniversário realizamos através dos meios digitais. Participante 5.

Facilitando as relações imediatas, distanciando os afetos presenciais. Não é a mesma coisa. Participante 33.

Acho que pode aproximar mais quem já vivia longe, e causou certo distanciamento de quem tinha o costume de se ver e estar perto, porque realmente uma coisa não substitui a outra. Participante 73.

Está ajudando a manter relações, mesmo que a distância, porém menos afetuosos. Participante 87.

A partir das respostas das pessoas participantes desta pesquisa reflete-se, preliminarmente, que a utilização das mídias e redes sociais neste período de pandemia pode trazer as aproximações diárias e momentâneas necessárias ao período de isolamento social, porém cabe refletir sobre o desafio de repensar os aspectos subjetivos que nos estão postos com relação às formas de relacionamentos, a superficialidade do conhecimento, aos vínculos e afetividades que, pelas perspectivas dos pesquisados, ainda não superam as relações sociais praticadas no cotidiano.

\section{Considerações Finais}

Esta pesquisa exploratória objetivou discutir como as relações sociais estão sendo impactadas no período de isolamento social e como as TIC trouxeram contribuições ou aumentaram os desafios neste período. A hipótese proposta é a nesta época de pandemia e isolamento social, as relações sociais experimentaram novas configurações que necessitaram ultrapassar o limite do contato físico, abrindo espaços para que o relacionamento social pudesse ser ressignificado, assim como novas formas de interação social através das TIC.

Para o público pesquisado, que utilizou mais TV, Facebook/Youtube e Google para buscar informações neste período de pandemia, as tecnologias trouxeram novas configurações de relacionamento social já que reuniões familiares, trabalho, lazer e estudos necessitaram de adaptação via TIC, atividades estas que, anteriormente, requisitariam um relacionamento pessoal, afetivo e/ou espacial.

As TIC impactaram positivamente para esta aproximação com amigos e familiares, colegas de trabalho e de estudo. Já, como um impacto negativo, as pessoas pesquisadas relataram que tais tecnologias puderam disseminar informações falsas, discursos de ódio, negacionismo da ciência, colaborando, neste sentido, com o distanciamento das afetividades. 
Contudo, embora as TIC contribuíram para ressignificar a interação das pessoas trazendo novas formas de relacionamentos e de configurações de sistemas urbanos, pela ótica dos pesquisados, estas tecnologias ainda não superaram as afetividades praticadas no cotidiano pessoal, trazendo um convite para próximas pesquisas desvelar e analisar a possível relação entre o uso das tecnologias e as afetividades praticadas nas relações sociais.

\section{REFERÊNCIAS}

Altamirano, O. L.; Ponce, W. M. Transmediacilina: combate síntomas de pandemia. 2020. In: http://www. meistudies.org/index.php/cmei/3cime/paper/view/789/514. Acesso em: dez.2020

Altermann, D. Qual a diferença entre redes sociais e mídias sociais? in: https://www.midiatismo.com.br/quala-diferenca-entre-redes-sociais-e-midias-sociais. Publicado em 06/09/2010. Acesso em: nov.2020.

Bauman, Z; Donskis, L. (2014). Cegueira Moral: a perda da sensibilidade na modernidade líquida. 1 ed. Rio de Janeiro: Zahar.

Bauman, Z. (2009). Vida Líquida. 2 ed. Rio de Janeiro: Zahar.

Bauman, Z. (2004). Amor Líquido: sobre a fragilidade dos laços humanos. Rio de Janeiro: Zahar.

Bezerra, M. A.; Cunha Junior,M. F.(2020)Cidades, espaçospúblicosecomportamento: discussõessobreocenário urbano no contexto de pandemia global. Disponível em: <https://www.observatoriodasmetropoles.net. br/cidades-espacos-publicos-e-comportamento-discussoes-sobre-o-cenario-urbano-no-contextode-pandemia-global/>. Acesso em: dez. 2020.

Caetano, R.; et al (2020). Pesquisa mostra impactos da pandemia nos municípios brasileiros: áreas mais impactadas foram educação e geração de emprego. Disponível em: <https://agenciabrasil.ebc.com. $\mathrm{br} / \mathrm{saude} /$ noticia/2020-10/pesquisa-mostra-impactos-da-pandemia-nos-municipios-brasileiros $>$. Acesso em: dez. 2020.

Castells, M. (2017). Redes de Indignação e Esperança: movimentos sociais na era da internet. 2 ed. rev. e atual. Rio de Janeiro: Zahar.

Castells, M. (2017) O Poder da Comunicação. 2 ed. Rio de Janeiro/São Paulo: Paz e Terra.

Castells, M. (2017) A Sociedade em Rede: a era da informação, economia, sociedade e cultura. Vol. 1. 18 ed. São Paulo: Paz e Terra.

Dapiné, A. (2020) Resiliência urbana e o impacto da Covid-19 nas cidades. Disponível em: <https://via.ufsc. br/resiliencia-urbana-covid-19/\#_ftn1>. Acesso em: dez. 2020.

Gomes Júnior, N. N.; Pereira, P. A. P. (2013) Necessidades do capital versus necessidades humanas no capitalismo contemporâneo: uma competição desigual. Argumentum, v. 5, n. 1, p. 50-63. .

Jenkins, H; Ford, S; Green, J. (2014). Cultura da Conexão: criando valor e significado por meio da mídia propagável. São Paulo: Aleph.

Lima, A. R. S. de; Pitta, A. M. F. (2019) Breve ensaio sobre as necessidades humanas básicas, o direito à saúde e a autonomia dos doentes mentais. Cadernos do CEAS: Revista Crítica de Humanidades, Salvador, $\mathrm{n}$. 246, jan./abr., p. 15-27. DOI: https://doi.org/10.25247/2447-861X.2019.n246.p15-27. 
Martino, L. M. S. (2014). Teoria das mídias digitais: linguagens, ambientes, redes. Petrópolis: Vozes.

Mcluhan, M. (2007) Os meios de comunicação como extensões do homem. São Paulo: Cultrix.

Meerow, S.; Newell, J. P.; Stults, M. (2016). Defining urban resilience: A review. Landscape and urban planning, v. 147, p. 38-49.

Pereira, M. D. et al. (2020). A pandemia de COVID-19, o isolamento social, consequências na saúde mental e estratégias de enfrentamento: uma revisão integrativa. Research: Society and Development, Aracaju, v. 1, n. 1, p. 1-29, Acesso em: mai.2020.

Santos, D. L.; Silva, R. M. (2020). Desafios e oportunidades para telessaúde em tempos da pandemia pela COVID-19: uma reflexão sobre os espaços e iniciativas no contexto brasileiro. Cadernos de Saúde Pública, [S.L.], v. 36, n. 5, p. 1-16. FapUNIFESP (SciELO). http://dx.doi.org/10.1590/0102-311x00088920.

Sayuri, J. (2020). Coronavírus: qual o impacto do isolamento nas sociedades mais 'abertas' do mundo. Disponível em: <https://www.bbc.com/portuguese/internacional-52042839>. Acesso em: dez. 2020. 